\title{
The safety and efficacy of CKD-497 in patients with acute upper respiratory tract infection and bronchitis symptoms: a multicenter, double-blind, double-dummy, randomized, controlled, phase II clinical trial
}

\author{
Seung Won Ra ${ }^{1 \#}$, Sun Young Kim", Yun Young Lim², Shin Jung Park ${ }^{2}$, Chin Kook Rhee ${ }^{3}$, Deog Kyeom Kim ${ }^{4}$, \\ Yong Bum Park ${ }^{5}$, Chang Youl Lee ${ }^{6}$, Hyoung Kyu Yoon ${ }^{7}$, Jeong-Woong Park ${ }^{8}$, Kwang Ha Yoo ${ }^{9}$ \\ ${ }^{1}$ Department of Internal Medicine, Ulsan University Hospital, University of Ulsan College of Medicine, Ulsan, Korea; ${ }^{2}$ Department of Botanical \\ Drug, Chong Kun Dang (CKD) Pharm Research Institute, Yongin-si, Gyeonggi-do, Korea; ${ }^{3}$ Division of Pulmonary, Allergy and Critical Care \\ Medicine, Department of Internal Medicine, Seoul St. Mary's Hospital, College of Medicine, The Catholic University of Korea, Seoul, Korea; \\ ${ }^{4}$ Department of Internal Medicine, Seoul National University Seoul Metropolitan Government Boramae Medical Center, Seoul National \\ University College of Medicine, Seoul, Korea; ${ }^{5}$ Division of Pulmonary, Allergy and Critical Care Medicine, Department of Internal Medicine, \\ Hallym University Kangdong Sacred Heart Hospital, Hallym University Medical Center, Seoul, Korea; ${ }^{6}$ Division of Pulmonary and Critical Care \\ Medicine, Department of Internal Medicine, Chuncheon Sacred Heart Hospital, Hallym University Medical Center, Chuncheon, Korea; ${ }^{7}$ Division \\ of Pulmonary and Critical Care Medicine, Department of Internal Medicine, Yeouido St Mary's Hospital, College of Medicine, The Catholic \\ University of Korea, Seoul, Korea; ${ }^{8}$ Division of Pulmonology and Allergy, Department of Internal Medicine, Gachon University Gil Medical Center, \\ Incheon, Korea; ${ }^{9}$ Division of Pulmonary, Allergy and Critical Care Medicine, Department of Internal Medicine, Konkuk University School of \\ Medicine, Seoul, Korea \\ Contributions: (I) Conception and design: KH Yoo, SW Ra, SY Kim, YY Lim, SJ Park; (II) Administrative support: SY Kim, YY Lim, SJ Park; (III) \\ Provision of study materials or patients: SW Ra, CK Rhee, DK Kim, YB Park, CY Lee, HK Yoon, JW Park, KH Yoo; (IV) Collection and assembly \\ of data: SW Ra, CK Rhee, DK Kim, YB Park, CY Lee, HK Yoon, JW Park, KH Yoo; (V) Data analysis and interpretation: SW Ra, SY Kim, YY Lim, \\ SJ Park; (VI) Manuscript writing: All authors; (VII) Final approval of manuscript: All authors. \\ "These authors contributed equally to this work. \\ Correspondence to: Kwang Ha Yoo, MD, PhD. Vice President, Director of Department of Internal Medicine, Director of Division of Pulmonology and \\ Allergy, Konkuk University Medical Center, 120-1 Neungdong-ro, Gwanjin-gu, Seoul 05030, Korea. Email: khyou@kuh.ac.kr.
}

Background: Acute upper respiratory tract infection (AURI) together with acute bronchitis is the most common illness worldwide. Botanical medicines used as expectorants and antitussives have proven to be effective while also having excellent safety margins. We aimed at evaluating the efficacy and safety of a new botanical drug, CKD-497, in patients with AURI and acute bronchitis.

Methods: In this phase 2 study, 225 patients were enrolled and randomly assigned to one of four treatment groups: placebo ( $n=55)$, Synatura ${ }^{\circledR}(n=49)$, CKD-497 $200 \mathrm{mg}(\mathrm{n}=68)$, or CKD-497 $300 \mathrm{mg}(\mathrm{n}=53)$. The study drugs were administered three times daily over the course of 7 days. Primary endpoint was the change in the bronchitis severity score (BSS) from baseline to day 7. Secondary endpoint was evaluated based on clinical response rates on days 4 and 7 . A safety analysis was also performed.

Results: Between baseline and day 7 , the mean BSS scores decreased significantly in each group $(\mathrm{P}<0.001)$ : $-4.04 \pm 1.85,-4.31 \pm 1.47,-4.09 \pm 1.48$, and $-4.28 \pm 1.69$. However, neither the CKD-497 nor Synatura ${ }^{\circledR}$ group showed any significant effect on the difference in BSS change $(\mathrm{P}=0.75)$. The rate of clinical response was higher in the CKD-497 $300 \mathrm{mg}$ group as compared to the placebo only on day $4(36 \%$ vs. $18 \% ; \mathrm{P}<0.05)$ and those having more severe bronchitis (phlegm score $\geq 3$ ) showed a significant reduction of total BSS in the Synatura ${ }^{\circledR}$ and CKD-497 groups $(\mathrm{P}=0.042)$. No significant adverse events were observed in either of the CKD-497 groups.

Conclusions: CKD-497 and even the positive control drug had no significant effect on BSS change in this phase 2 clinical trial. However, CKD-497 $300 \mathrm{mg}$ had a mild but significant clinical improvement in early 
bronchitis patients with more severe phlegm. Considering both efficacy and safety, a future study using $300 \mathrm{mg}$ of CKD-497 with a shorter-term endpoint is warranted in patients with more severe bronchitis symptoms.

Keywords: Acute respiratory tract infection; bronchitis; bronchitis severity score (BSS); CKD-497

Submitted May 22, 2020. Accepted for publication Oct 22, 2020.

doi: $10.21037 /$ jtd-20-1567

View this article at: http://dx.doi.org/10.21037/jtd-20-1567

\section{Introduction}

Acute upper respiratory tract infection (AURI) and acute bronchitis $(\mathrm{AB})$ are among the most common diseases reported in outpatient settings (1). On average, adults are diagnosed with AURI and AB, often called the common cold, two to five times in a year $(2,3)$. These diseases are associated with $40 \%$ of instances of absenteeism at work and $10 \%$ of emergent visits, which cause a huge social and economic burden (4-6). AURI and $A B$ are defined as irritation and swelling in the airway without any symptoms of pneumonia $(1,7)$. Generally, AURI is used to refer to pharyngitis, laryngitis, tonsillitis, and rhinitis, and its symptoms include cough, sore throat, runny nose, nasal congestion, headache, sneezing, malaise, and myalgia $(7,8)$. The most common etiology of AURI and $A B$ is infection with viruses including rhinovirus, influenza virus, adenovirus, enterovirus, and respiratory syncytial virus $(9,10)$. These viruses directly invade the upper airway, leading to the development of AURI and $\mathrm{AB}$. One of the body's defenses for preventing the entry of these pathogens into the airway is mucus (11).

In a healthy individual, mucus traps these foreign organisms and transports them to the pharynx by mucociliary clearance, thus preventing them entering the deep respiratory system (12-14). However, this mucous homeostasis can sometimes fail to prevent AURI and $\mathrm{AB}$, resulting in thick mucus, impairment of mucociliary clearance and coughing (14-16). In terms of treatment, the primary requirement for AURI and $A B$ is relief from an increase in mucus production, i.e., phlegm, and cough using expectorants and antitussives. With regard to evaluating the effectiveness of expectorants and antitussives, the bronchitis severity score (BSS) consisting of five components including cough, phlegm production, rales/rhonchi, chest pain during coughing, and dyspnea assessed by physicians is considered a valid measurement tool and the change of total BSS is considered to be important (17-19).

Recently, botanical medicines have been found to be effective and safe for the treatment of respiratory diseases of both adult and children in double-blind, placebo-controlled clinical trials (17-19). Their formulations are capsule, syrup or tablet. Synatura ${ }^{\circledR}$ (a botanical drug chiefly comprising ivy leaf extract) has been reported to be effective for cough and phlegm reduction $(18,19)$; ivy leaf extract has been approved for these indications by the European Medicines Agency (EMA). CKD-497, a botanical expectorant, has been developed by CKD Pharm; its pharmacological efficacy has been proven in vitro and in vivo (20). Hence, in this phase II clinical trial, we aimed to determine the efficacy and safety profile of CKD-497.

\section{Methods}

\section{Study design}

The trial included subjects with cough and phlegm caused by AURI and AB. This was a randomized, double-blind, placebo- and active component-controlled, four-group parallel design trial conducted in 15 centers in Korea from June 8, 2018 (when the first patient was enrolled) to March 21, 2019 (when the last patient was enrolled). The trial was conducted according to the principles of the Declaration of Helsinki and Korean Good Clinical Practice guidelines, and written informed consent was obtained from all patients. The trial protocol was approved by the Korean Food and Drug Administration (approval no. 176AURI/AB17014) and by the institutional and review board (IRB) at each center. This study was registered in the Clinical Trials Registry in Korea (31630) and Clinicaltrial.gov (NCT03726853) before the enrollment was started.

\section{Patient selection and procedures}

Two hundred and thirty-one patients between the ages of 19 and 75 years were screened. Of these, 225 patients who provided written informed consent were enrolled. The following subjects were included: non-smokers (subjects who had stopped smoking for more than a year at the time 
A

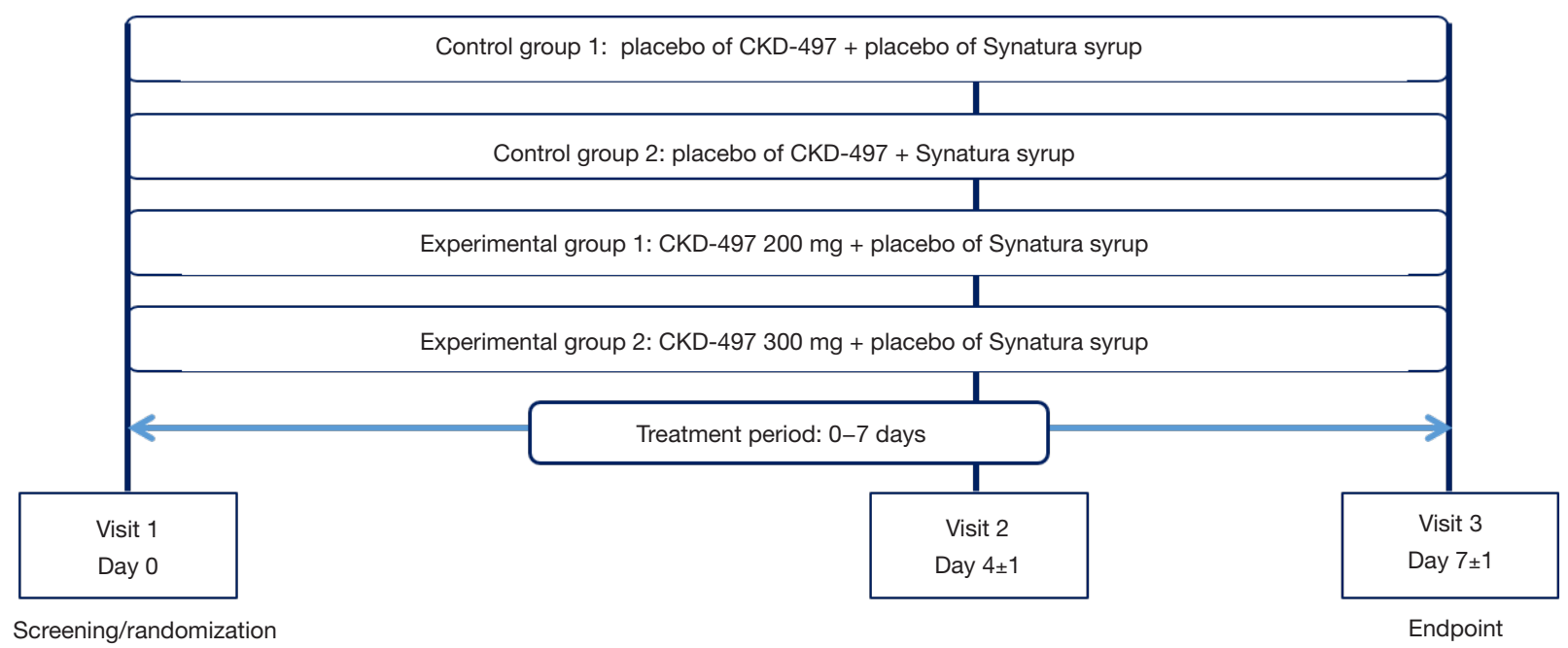

B

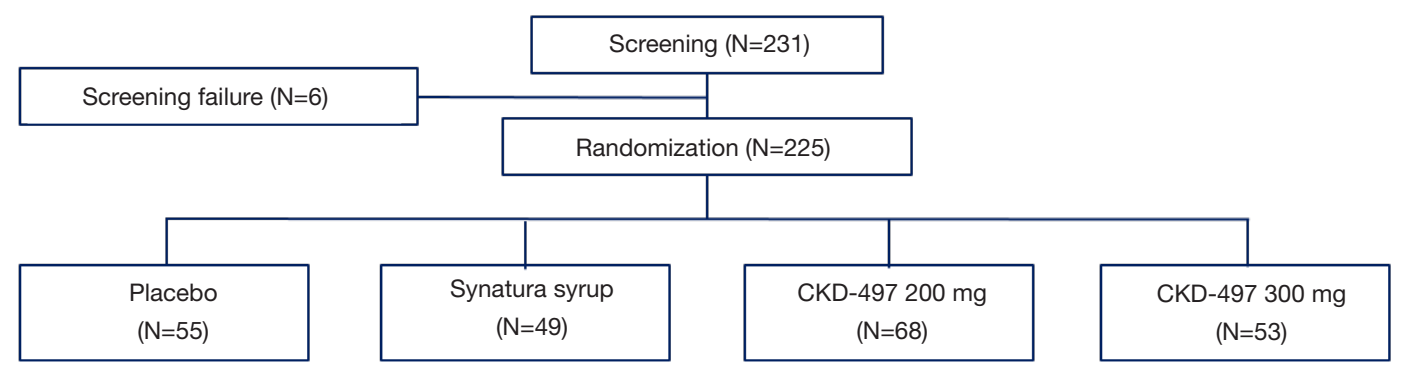

Figure 1 Study design and flowchart of study participants. (A) A phase 2, randomized, double-blind, multi-center, parallel-group trial to evaluate the efficacy and safety of CKD-497 in patients with cough and phlegm due to acute upper respiratory infection and acute bronchitis; (B) the patients were assigned to placebo, Synatura syrup, CKD-497 200 or $300 \mathrm{mg}$.

of enrollment were also eligible for inclusion), and subjects having symptoms such as cough and phlegm along with AURI and $A B$ within $72 \mathrm{~h}$ of the time of enrollment and a BSS of $\geq 5$ along with a cough and phlegm score of $\geq 2$. The following subjects were excluded from the trial: those who were considered to need antibiotics during the trial; those with pneumonia, asthma, chronic obstructive pulmonary disease, tuberculosis, bronchiectasis, tumors, severe diabetes, hypertension, or any other disease that could interfere with the trial outcome; and lactating or pregnant women.

The patients who met the inclusion criteria were randomized at a ratio of 1:1:1:1 at visit 1 . As shown in Figure 1, the patients were divided into the following four groups: placebo $(\mathrm{n}=55)$, active control (Synatura ${ }^{\circledR}$, $\mathrm{n}=49)$, CKD-497 $200 \mathrm{mg}(\mathrm{n}=68)$, and CKD-497 $300 \mathrm{mg}$ $(\mathrm{n}=53)$. In all the groups, the respective intervention was administered three times a day for 7 days. The patients' BSS and improvement of symptoms at hospital visit 2 (day $4 \pm 1$ ) and visit 3 (day $7 \pm 1$ ) were assessed by physicians. Furthermore, at every visit, the patients were followed up to confirm drug compliance and record concomitant medications, vital signs, blood test results, adverse events, and adverse drug reactions. Additionally, drug and disease history of the patients was investigated, and urine human chorionic gonadotropin (HCG) test, chest X-ray, and electrocardiography (ECG) were conducted at the screening (visit 1) and only urine HCG test and chest X-ray were performed at the final visit (visit 3).

\section{Assessment}

To quantify the efficacy of CKD-497 on AURI and $\mathrm{AB}$, BSS and assessment of patients' improvement by 
investigators and patients themselves were used as variables in the evaluation. Regarding BSS, physicians rated the patients' symptoms, including cough, phlegm production, rales/rhonchi, chest pain during coughing, and dyspnea, at every visit on a scale of 0 to $4(0=$ none, $1=$ mild, $2=$ moderate, $3=$ severe, and $4=$ very severe). The primary endpoint was the change in the total mean BSS at visit 3 from baseline (mean BSS at visit 3-mean BSS at visit 1). The secondary endpoints were as follows. (I) The first was the change in the total mean BSS at visit 2 from baseline visit. (II) The second was the change in the mean BSS for cough or phlegm at visit 2 or 3 from baseline. (III) The third was the change from visit 1 to visit 2 or 3 in the component of BSS (cough or phlegm) that rating was equal to and greater than 3 at visit 1 . (IV) The fourth was the change from visit 1 to visit 2 or 3 in the total mean BSS, whose rating of cough or phlegm was equal to and higher than 3 at visit 1. (V) The final one was the improvement reported by investigators or the patients' themselves on a scale of 1 to $5(1=$ complete recover, $2=$ markedly recover, $3=$ slightly recover, $4=$ same, $5=$ worse) at visits 2 and 3 compared to the status at visit 1 . Patients who reported a score of 1 or 2 were considered to show improvement and those who reported a score of 3 and higher were considered to be "nonimprovement" group. To assess adverse events and adverse drug reactions (safety analysis), the following data collected by the investigators were analyzed: vital signs, chest X-ray, ECG findings, blood test results, and concomitant use of drugs.

\section{Statistical analysis}

Statistical analyses were performed using $\mathrm{SAS}^{\circledR}$ software (version 9.4; SAS Institute Inc., Cary, NC, USA). All tests were two-tailed, and significance was set at $\mathrm{P}<0.05$. The data set for evaluating the effect of CKD-497 was as per that in Figure 1. The sample size of each group was calculated as 55 on average if the difference of the change in BSS from baseline to visit 3 between the CKD-497 and placebo groups was considered as 1.6, the standard deviation (SD) 2.3 , significance level $5 \%$, statistical power $90 \%$, and dropout rate $20 \%$ (21). In total, more than 220 enrollments $(55 \times 4$ groups) were needed, and the actual number of subjects enrolled was 225 . For the primary and secondary endpoints, each experimental group was compared with the control or placebo group by using the Kruskal-Wallis test and Bonferroni post-hoc test after determining the changes in BSS at visit 2 or 3 compared to the BSS at visit 1 . Then the BSS data adjusted for sex, smoking history, age, visiting month or season, clinical institute, personal disease history, and BSS at visit 1 was analyzed in additional secondary endpoint. With regard to symptom improvement, the Chisquare test was conducted to compare the experimental groups with the placebo or positive control group. Regarding the safety assessment, symptom incidences were indicated in percentages, and the data was analyzed using Chi-square test.

\section{Results}

\section{Effects of CKD-497 on the BSS}

Baseline characteristics and medical history of study subjects were not statistically different among the four groups (Table 1 and Table S1). As shown in Table S2, all but two patients complied with the drug schedule. BSS scores at baseline were $5.82 \pm 1.20,5.63 \pm 0.88,5.68 \pm 0.98$, and $5.72 \pm 0.91$ in the placebo, Synatura ${ }^{\circledR}, \mathrm{CKD}-497200 \mathrm{mg}$, and CKD-497 $300 \mathrm{mg}$ groups, respectively $(\mathrm{P}>0.05)$. To evaluate the effect of CKD-497 200 and $300 \mathrm{mg}$ on $\mathrm{AURI}$ and $\mathrm{AB}$ at visit 3, changes in the total BSS average between visit 3 and 1 (mean BSS at visit 3-mean BSS at visit 1$)$ were analyzed. The changes in the mean BSS were $-4.04 \pm 1.85,-4.31 \pm 1.47,-4.09 \pm 1.48$, and $-4.28 \pm 1.69$ in the placebo, positive control, CKD-497 $200 \mathrm{mg}$, and CKD-497 $300 \mathrm{mg}$ groups, respectively (Table 2), suggesting significant intragroup differences in all groups (BSS at visit $1 v s$. BSS at visit 3 in each group, $\mathrm{P}<0.001$ ). However, neither the CKD-497 nor positive control group showed significant effect on the primary endpoint compared to the placebo group $(\mathrm{P}=0.75)$. In the per-protocol set, the non-compliance patients were excluded, and the results were the same.

\section{Effect of CKD-497 on the secondary endpoints}

For the secondary endpoints, five different analyses were performed. In the first, the effect of CKD-497 200 and $300 \mathrm{mg}$ at visit 2 was compared to that at visit 1 , and the results were as follows: $-2.25 \pm 1.75$ (placebo group), $-2.76 \pm 1.25$ (positive control group), $-2.57 \pm 1.51$ (CKD-497 $200 \mathrm{mg}$ group), and $-2.87 \pm 1.48$ (CKD-497 $300 \mathrm{mg}$ group) (Table 2). The intergroup difference was not statistically significant $(\mathrm{P}=0.22)$. To determine whether CKD-497 200 or $300 \mathrm{mg}$ 
Table 1 Baseline characteristics of study subjects

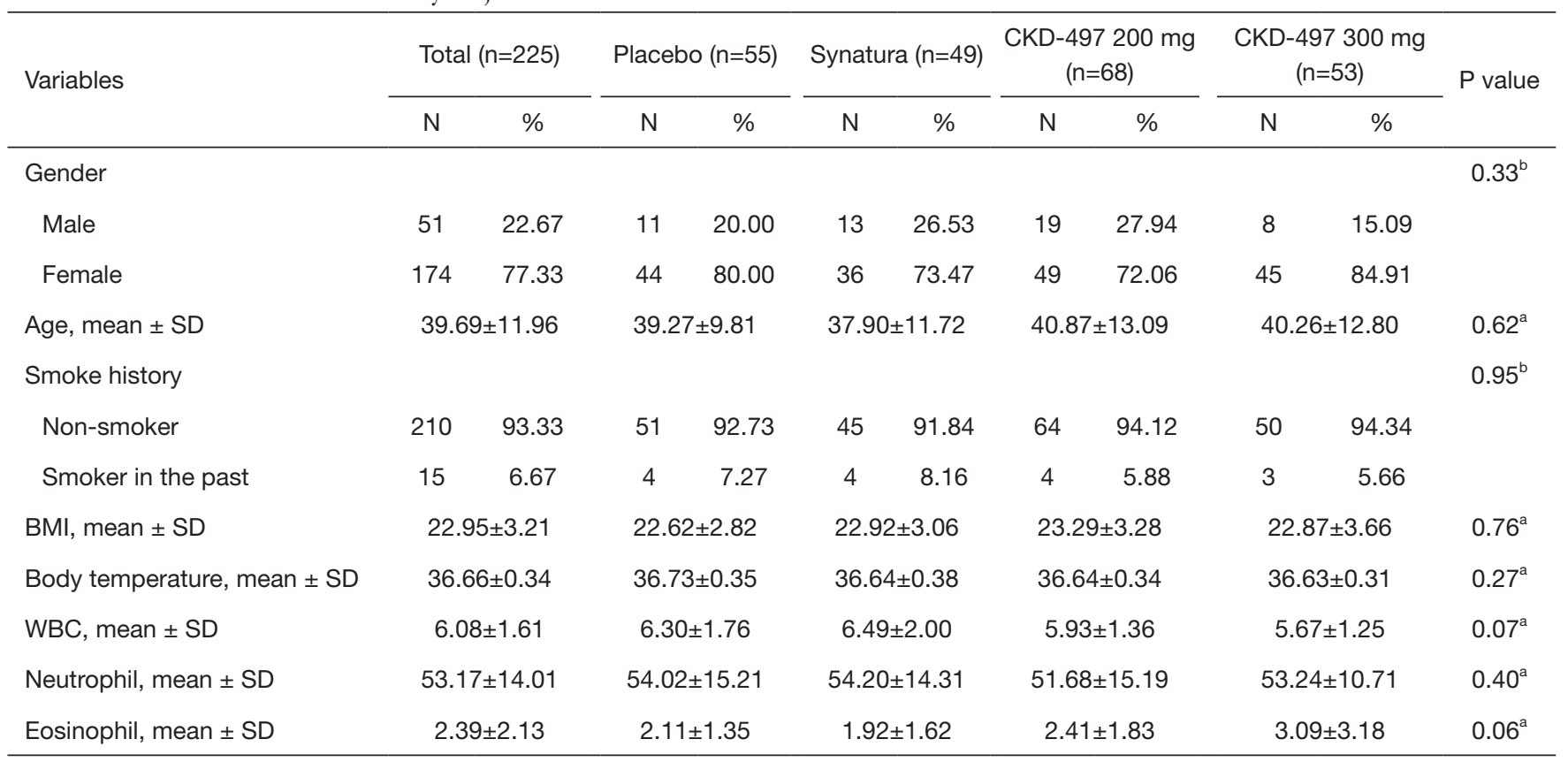

a, Kruskal-Wallis test; ${ }^{\mathrm{b}}$, Chi-square test. SD, standard deviation; BMI, body mass index; WBC, white blood cell.

Table 2 Primary efficacy analysis of the change in total BSS according to groups

\begin{tabular}{|c|c|c|c|c|}
\hline Variables (BSS total) & Placebo $(n=55)$ & Synatura $(n=49)$ & CKD-497 200 mg $(n=68)$ & CKD-497 $300 \mathrm{mg}(\mathrm{n}=53)$ \\
\hline Day 4 (visit 2), mean (SD) & $3.56(2.32)$ & $2.88(1.36)$ & $3.10(1.53)$ & $2.85(1.59)$ \\
\hline Day 7 (visit 3), mean (SD) & $1.78(2.02)$ & $1.33(1.28)$ & $1.59(1.37)$ & $1.43(1.77)$ \\
\hline Change (day 4-baseline) & $-2.25(1.75)$ & $-2.76(1.25)$ & $-2.57(1.51)$ & $-2.87(1.48)$ \\
\hline Change (day 7-baseline) & $-4.04(1.85)$ & $-4.31(1.47)$ & $-4.09(1.48)$ & $-4.28(1.69)$ \\
\hline$P$ value ${ }^{a}$ & \multicolumn{4}{|c|}{0.75} \\
\hline
\end{tabular}

${ }^{a}$, Kruskal-Wallis test. BSS, bronchitis severity score; SD, standard deviation.

affected the BSS for cough or phlegm at visits 2 or 3 , we determined the differences between visit 2 or 3 and visit 1. As shown in Table S3, the results showed no clinically significant difference in statistics.

Analysis of covariance with an adjustment for the clinical institute and baseline BSS was also performed to compare the change in BSS from baseline to visit 2 or 3 between the four groups and showed no differences (Table S4). After adjustment, we identified the patients whose total BSS average was equal to and greater than 3 (tBSS3) at visit 1 and recorded the changes in tBSS 3 at visit 2 or 3 . Changes in the total average of $\mathrm{tBSS} 3$ at visit 2 or 3 compared to tBSS3 at visit 1 showed no effect of CKD-497 (data not shown). Furthermore, the patients whose average cough BSS or phlegm BSS was equal to and greater than 3 (cBSS3 or pBSS3) at visit 1 were identified, and the changes in the mean of total BSS at each visit was shown in Figure 2 (Tables S5,S6). Interestingly, although there was no difference of the change in the mean of total BSS from baseline among the four groups including only those with cBSS3 (Figure $2 A$ ), the changes at visit 2 showed a statistical difference $\left({ }^{*}, \mathrm{P}=0.042\right.$ by Kruskal-Wallis test) in those with 
A

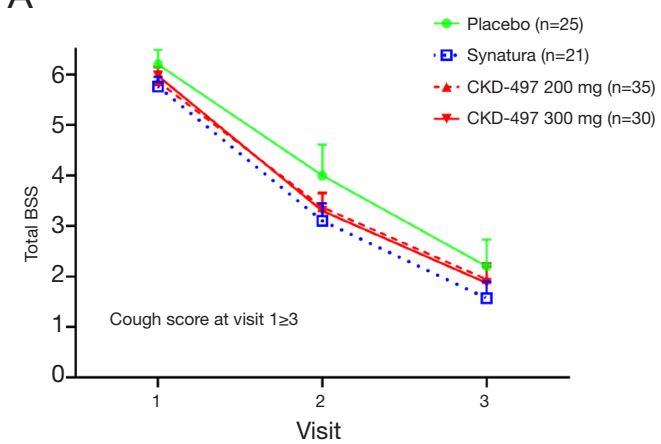

B

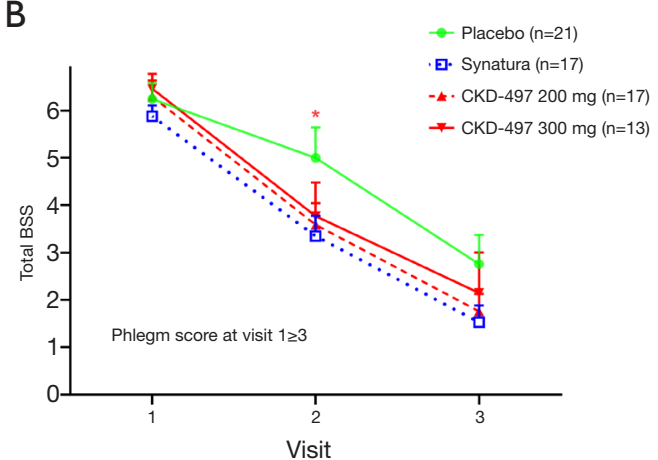

Figure 2 The mean of total BSS in study groups of placebo, Synatura, CKD-497 200 or $300 \mathrm{mg}$ at each visit. (A) The changes of the mean of total BSS from baseline showed no significant difference among the four groups including only those with cough score at visit $1 \geq 3$; (B) the changes of the mean of total BSS at visit 2 showed a statistical difference in the four groups including only those with phlegm score at visit $1 \geq 3\left(^{*}, \mathrm{P}=0.042\right.$ by Kruskal-Wallis test). Bars indicate standard error of means. BSS, bronchitis severity score.

A

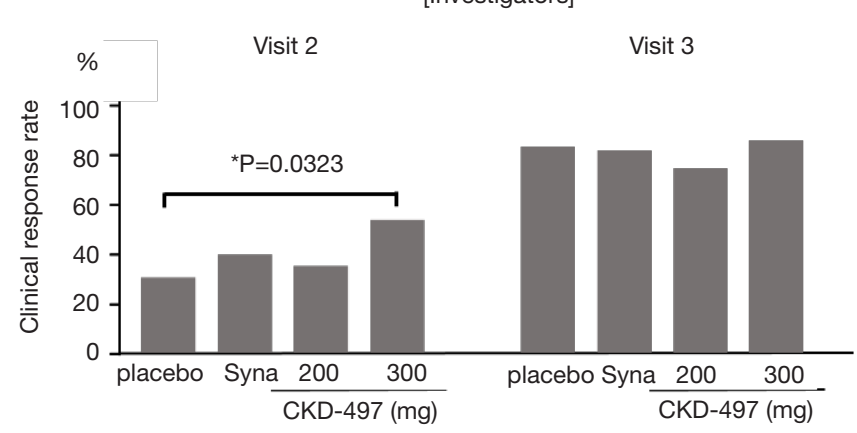

B

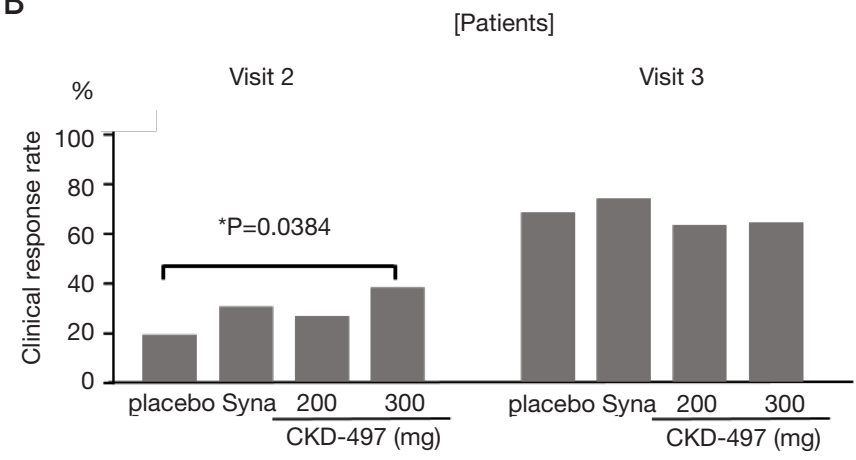

Figure 3 Clinical response rate of symptom reported by investigators and patients. (A) Improvement of symptoms at visit 2 and 3 was asked to investigators and analyzed their responding; (B) improvement of symptoms at visit 2 and 3 was assessed by patients and analyzed their responding. *, Chi-square test between CKD-497 $300 \mathrm{mg}$ vs. placebo.

pBSS3 (Figure 2B).

The investigators and patients rated the improvement in symptoms at visit 2 and 3 compared to the status at visit 1 (Figure 3). Evaluation of patients' recovery at visit 2 from the corresponding status at visit 1 indicated that compared to the placebo treatment, the treatment with CKD-497 $300 \mathrm{mg}$ significantly improved symptoms. More importantly, both the investigators and patients confirmed significant improvements at visit $2(\mathrm{P}=0.0323,0.0384)$.

\section{Safety assessment}

In total, there were 27 adverse events in 21 patients $(9.33 \%)$, and intergroup differences were not significant $(\mathrm{P}=0.84$, Table 3). There were 6 adverse events among 5 patients $(9.43 \%)$ in the CKD-497 $300 \mathrm{mg}$ group and 10 events among 8 patients (11.76\%) in the CKD-497 $200 \mathrm{mg}$ group. Similarly, there were 5 events of adverse effects among 4 patients $(8.16 \%)$ in the positive control group and 6 events among 4 patients $(7.27 \%)$ in the placebo group (Table 3).

Overall, there were 10 cases of adverse drug reactions in 8 patients $(3.56 \%)$, and intergroup differences were not significant $(\mathrm{P}=0.34)$. There were no cases of adverse drug reactions in the CKD-497 $300 \mathrm{mg}$ group, and 3 cases among 3 patients (4.41\%) in the CKD-497 $200 \mathrm{mg}$ group. In the positive control and placebo groups, there were 4 and 3 cases of adverse drug effects in $3(6.12 \%)$ and 2 (3.64\%) patients, respectively. There was no severe adverse events or severe adverse drug reactions. 


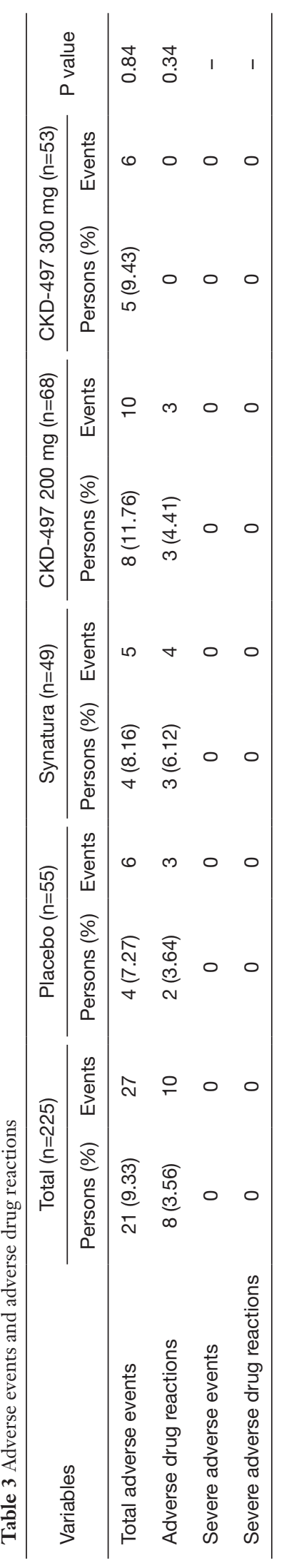

\section{Discussion}

The purpose of this phase II study was to test the safety and efficacy of CKD-497, a new botanical drug developed by CKD Pharm., which could facilitate the treatment of AURI and $A B$ and prevent progression of severe respiratory symptoms. It is notable that CKD-497 consists of edible botanical sources (20). Furthermore, the safety assessment conducted in this study revealed no concerning adverse drug effect or severe adverse events. In this phase II clinical trial of CKD-497, primary and secondary endpoints were evaluated in various analyses using a valid measurement tool of BSS. With regard to the fact that the primary outcome did not reach a statistical significance in this trial, this finding was attributable to the milder symptoms, reflected by low BSS values at baseline in our study subjects than previous studies (17-19,21). We calculated the sample size based on the previous study (21) that enrolled patients with more severe BSS than our study, which could be the main reason that CKD-497 showed milder effect on this trial.

It is well-established and accepted that mild viral URIs resolve spontaneously without any medications. Not only in CKD-497 and active comparator group but also in placebo group, the total BSS showed significant improvements between baseline visit 1 and 2 or 3 . However, it is notable that among those with more severe phlegm, there was a significant difference in BSS at visit 2 but not at visit 3 suggesting earlier recovery in CKD-497 $300 \mathrm{mg}$ group than placebo group, which was associated with clinical improvement in the group. Although the primary endpoint did not reach a statistical significance, the change in BSS was numerically larger in the experimental drug groups than in the placebo group; however, the difference was not significant, which could be due to a lack of efficacy of the drug CKD497. Moreover, we did not consider multiple comparisons of four groups when we calculated sample size as shown in submitted protocol (NCT03726853).

Three limitations of this trial should be noted. First, the lack of study power and the characteristics of the study subjects who had milder symptoms at baseline resulted in no effect on the primary endpoint. However, with regard to the secondary endpoints, it was important that both investigators and patients in the CKD-497 $300 \mathrm{mg}$ group reported significant improvement of symptoms at visit 2. In addition, total BSS decreased at visit 2 in subgroup analysis of the patients having more phlegm score. These findings 
suggest that CKD-479 could favorably treat specific symptoms of AURI or AB. Since the present study is a phase II study to determine dose of study drugs and investigate a little more safety aspect rather than efficacy, a further study of phase III trial focusing on the efficacy of $300 \mathrm{mg}$ CKD497 with a larger sample to test for any clinical efficacy of CKD-497 is needed in patients with more severe bronchitis symptoms.

Second, there was a lack of gender balance in our study on randomization. The ratio was $8: 2$ between female and male in the order. This imbalance was more affected by the small sample size. Again, further investigation with larger number of study subjects or stratified randomization according to gender would supplement our investigation.

Third, we analyzed our data using analysis of variance, which is a predefined statistical method, as opposed to using a generalized estimating equation (GEE) model, which can take the time effect into consideration. Although the missing data of outcome occurred only in two subjects and the results were the same when we reanalyzed our data using the GEE method, the sample size calculated by the two methods would be different on planning study design and might have affected our results. Further study with a more sophisticated calculation of sample size based on accurate statistical methods is needed.

In conclusion, this phase II clinical trial showed that there was no significant effect of CKD-497 and the positive control drug on BSS change. However, CKD-497 $300 \mathrm{mg}$ had a mild but significant clinical improvement in early bronchitis patients with more severe phlegm. Considering both efficacy and safety, a future study using $300 \mathrm{mg}$ of CKD-497 with a shorter-term endpoint is warranted in patients with more severe bronchitis symptoms.

\section{Acknowledgments}

The trial was financially supported by CKD Pharm. The company also supported with statistical analyses of the trial results and another statistician (JS Lee) in an academic institution independently checked if the data has been properly analyzed.

Funding: CKD Pharm.

\section{Footnote}

Data Sharing Statement: Available at http://dx.doi. org/10.21037/jtd-20-1567

Conflicts of Interest: All authors have completed the ICMJE uniform disclosure form (available at http://dx.doi. org/10.21037/jtd-20-1567). Dr. SYK, Dr. PhD. YYL and Ms. SJP report personal fees from CKD pharm, during the conduct of the study. The other authors have no conflicts of interest to declare.

Ethical Statement: The authors are accountable for all aspects of the work in ensuring that questions related to the accuracy or integrity of any part of the work are appropriately investigated and resolved. The trial protocol was approved by the Korean Food and Drug Administration (approval no. 176AURI/AB1714) and by the institutional and review board (IRB) at each center. The trial was conducted according to the principles of the Declaration of Helsinki and Korean Good Clinical Practice guidelines, and written informed consent was obtained from all patients.

Open Access Statement: This is an Open Access article distributed in accordance with the Creative Commons Attribution-NonCommercial-NoDerivs 4.0 International License (CC BY-NC-ND 4.0), which permits the noncommercial replication and distribution of the article with the strict proviso that no changes or edits are made and the original work is properly cited (including links to both the formal publication through the relevant DOI and the license). See: https://creativecommons.org/licenses/by-nc-nd/4.0/.

\section{References}

1. Thomas M, Bomar PA. Upper respiratory tract infection. [Updated 2020 Oct 28]. In: StatPearls [Internet]. Treasure Island (FL): StatPearls Publishing 2020. Available online: https://www.ncbi.nlm.nih.gov/books/NBK532961/

2. Arroll B. Common cold. BMJ Clin Evid 2011;2011:1510.

3. Winther B, Gwaltney JM, Mygind N, et al. Viral-induced rhinitis. Am J Rhinol 1998;12:17-20.

4. Fendrick AM, Monto AS, Nightengale B, et al. The economic burden of non-influenza-related viral respiratory tract infection in the United States. Arch Intern Med 2003;163:487-94.

5. National Hospital Ambulatory Medical Care Survey: 2011 Outpatient Department Summary Tables. [cited 2015 Mar 28]. Available online: https://www.cdc.gov/nchs/data/ahcd/ 
nhamcs_emergency/2011_ed_web_tables.pdf

6. Kirkpatrick GL. The common cold. Prim Care 1996;23:657-75.

7. Kinkade S, Long NA. Acute bronchitis. Am Fam Physician 2016;94:560-5.

8. Yoon YK, Park CS, Kim JW, et al. Guidelines for the antibiotic use in adults with acute upper respiratory tract infections. Infect Chemother 2017;49:326-52.

9. Clark TW, Medina MJ, Batham S, et al. Adults hospitalised with acute respiratory illness rarely have detectable bacteria in the absence of COPD or pneumonia; viral infection predominates in a large prospective UK sample. J Infect 2014;69:507-15.

10. Gencay M, Roth M, Christ-Crain M, et al. Single and multiple viral infections in lower respiratory tract infection. Respiration 2010;80:560-7.

11. Tripathi S, Nikhare A, Sharma G, et al. Safety and tolerability of extended-release guaifenesin in patients with cough, thickened mucus and chest congestion associated with upper respiratory tract infection. Drug Healthc Patient Saf 2019;11:87-94.

12. Rogers DF. Physiology of airway mucus secretion and pathophysiology of hypersecretion. Respir Care 2007;52:1134-46.

13. Rose MC, Voynow JA. Respiratory tract mucin genes and mucin glycoproteins in health and disease. Physiol Rev 2006;86:245-78.

14. Fahy JV, Dickey BF. Airway mucus function and dysfunction. N Engl J Med 2010;363:2233-47.

15. Houtmeyers E, Gosselink R, Gayan-Ramirez G, et al. Regulation of mucociliary clearance in health and disease.

Cite this article as: Ra SW, Kim SY, Lim YY, Park SJ, Rhee CK, Kim DK, Park YB, Lee CY, Yoon HK, Park JW, Yoo KH. The safety and efficacy of CKD-497 in patients with acute upper respiratory tract infection and bronchitis symptoms: a multicenter, double-blind, double-dummy, randomized, controlled, phase II clinical trial. J Thorac Dis 2021;13(1):1-9. doi: $10.21037 /$ jtd-20-1567
Eur Respir J 1999;13:1177-88.

16. Maestrelli P, Saetta M, Mapp CE, et al. Remodeling in response to infection and injury: airway inflammation and hypersecretion of mucus in smoking subjects with chronic obstructive pulmonary disease. Am J Respir Crit Care Med 2001;164:S76-80.

17. Kim WY, Park MJ, Rhee CK, et al. HL301 versus umckamin in the treatment of acute bronchitis: a phase III, randomized, controlled, double-blind, multicenter study. Curr Med Res Opin 2020;36:503-8.

18. Kemmerich B, Eberhardt R, Stammer H. Efficacy and tolerability of a fluid extract combination of thyme herb and ivy leaves and matched placebo in adults suffering from acute bronchitis with productive cough. A prospective, double-blind, placebo-controlled clinical trial. Arzneimittelforschung 2006;56:652-60.

19. Kemmerich B. Evaluation of efficacy and tolerability of a fixed combination of dry extracts of thyme herb and primrose root in adults suffering from acute bronchitis with productive cough. A prospective, double-blind, placebocontrolled multicentre clinical trial. Arzneimittelforschung 2007;57:607-15.

20. Chae HS, Kim SY, Pel P, et al. Standardized Extract of Atractylodis Rhizoma Alba and Fructus Schisandrae Ameliorates Coughing and Increases Expectoration of Phlegm. Molecules 2020;25:3064.

21. Matthys H, Lizogub VG, Malek FA, et al. Efficacy and tolerability of EPs 7630 tablets in patients with acute bronchitis: a randomised double-blind, placebo-controlled dose-finding study with a herbal drug preparation from Pelargonium sidoides. Curr Med Res Opin 2010;26:1413-22. 
Table S1 Patients' medical history

\begin{tabular}{|c|c|c|c|c|c|c|}
\hline Variables & $\begin{array}{l}\text { Total (n=225), persons } \\
\text { (\%) [case] }\end{array}$ & $\begin{array}{l}\text { Placebo (n=55), } \\
\text { persons (\%) [case] }\end{array}$ & $\begin{array}{l}\text { Synatura syrup ( } n=49) \text {, } \\
\text { persons (\%) [case] }\end{array}$ & $\begin{array}{l}\text { CKD-497 } 200 \mathrm{mg}(\mathrm{n}=68), \\
\text { - persons (\%) [case] }\end{array}$ & $\begin{array}{l}\text { CKD-497 } 300 \mathrm{mg}(\mathrm{n}=53), \\
\text { persons (\%) [case] }\end{array}$ & $P$ value \\
\hline Total & 53 (23.56) [99] & $13(23.64)[24]$ & $11(22.45)[26]$ & 14 (20.59) [28] & 15 (28.30) [21] & $0.7942^{b}$ \\
\hline Gastrointestinal disorders & $11(4.89)[13]$ & $2(3.64)[2]$ & $3(6.12)[3]$ & $4(5.88)[6]$ & $2(3.77)[2]$ & $0.8840^{\mathrm{a}}$ \\
\hline Gastrooesophageal reflux disease & $4(1.78)[4]$ & $1(1.82)[1]$ & $0(0.00)[0]$ & $2(2.94)[2]$ & $1(1.89)[1]$ & $0.9066^{\mathrm{a}}$ \\
\hline Chronic gastritis & $2(0.89)[2]$ & $1(1.82)[1]$ & $0(0.00)[0]$ & $1(1.47)[1]$ & $0(0.00)[0]$ & $1.0000^{\mathrm{a}}$ \\
\hline Gastritis & $2(0.89)[2]$ & $0(0.00)[0]$ & $1(2.04)[1]$ & $0(0.00)[0]$ & $1(1.89)[1]$ & $0.3537^{\mathrm{a}}$ \\
\hline Colitis & $1(0.44)[1]$ & $0(0.00)[0]$ & $1(2.04)[1]$ & $0(0.00)[0]$ & $0(0.00)[0]$ & $0.2178^{\mathrm{a}}$ \\
\hline Colitis ulcerative & $1(0.44)[1]$ & $0(0.00)[0]$ & $0(0.00)[0]$ & $1(1.47)[1]$ & $0(0.00)[0]$ & $1.0000^{\mathrm{a}}$ \\
\hline Duodenitis & $1(0.44)[1]$ & $0(0.00)[0]$ & $0(0.00)[0]$ & $1(1.47)[1]$ & $0(0.00)[0]$ & $1.0000^{\mathrm{a}}$ \\
\hline Gingival bleeding & $1(0.44)[1]$ & $0(0.00)[0]$ & $0(0.00)[0]$ & $1(1.47)[1]$ & $0(0.00)[0]$ & $1.0000^{\mathrm{a}}$ \\
\hline Irritable bowel syndrome & $1(0.44)[1]$ & $0(0.00)[0]$ & $1(2.04)[1]$ & $0(0.00)[0]$ & $0(0.00)[0]$ & $0.2178^{\mathrm{a}}$ \\
\hline Vascular disorders & $10(4.44)[10]$ & $3(5.45)[3]$ & $2(4.08)[2]$ & $4(5.88)[4]$ & $1(1.89)[1]$ & $0.7728^{\mathrm{a}}$ \\
\hline Hypertension & $7(3.11)[7]$ & $2(3.64)[2]$ & $1(2.04)[1]$ & $3(4.41)[3]$ & $1(1.89)[1]$ & $0.8782^{\mathrm{a}}$ \\
\hline Varicose vein & $2(0.89)[2]$ & $1(1.82)[1]$ & $0(0.00)[0]$ & $1(1.47)[1]$ & $0(0.00)[0]$ & $1.0000^{\mathrm{a}}$ \\
\hline Peripheral venous disease & $1(0.44)[1]$ & $0(0.00)[0]$ & $1(2.04)[1]$ & $0(0.00)[0]$ & $0(0.00)[0]$ & $0.2178^{\mathrm{a}}$ \\
\hline $\begin{array}{l}\text { Musculoskeletal and connective tissue } \\
\text { disorders }\end{array}$ & $9(4.00)[12]$ & $3(5.45)[5]$ & $4(8.16)[5]$ & $1(1.47)[1]$ & $1(1.89)[1]$ & $0.2503^{\mathrm{a}}$ \\
\hline Back pain & $2(0.89)[2]$ & $1(1.82)[1]$ & $1(2.04)[1]$ & $0(0.00)[0]$ & $0(0.00)[0]$ & $0.4607^{\mathrm{a}}$ \\
\hline Osteoarthritis & $2(0.89)[2]$ & $0(0.00)[0]$ & $1(2.04)[1]$ & $1(1.47)[1]$ & $0(0.00)[0]$ & $0.7086^{\mathrm{a}}$ \\
\hline Rotator cuff syndrome & $2(0.89)[2]$ & $1(1.82)[1]$ & $1(2.04)[1]$ & $0(0.00)[0]$ & $0(0.00)[0]$ & $0.4607^{\mathrm{a}}$ \\
\hline Arthralgia & $1(0.44)[1]$ & $0(0.00)[0]$ & $0(0.00)[0]$ & $0(0.00)[0]$ & $1(1.89)[1]$ & $0.4533^{\mathrm{a}}$ \\
\hline Facet joint syndrome & $1(0.44)[1]$ & $1(1.82)[1]$ & $0(0.00)[0]$ & $0(0.00)[0]$ & $0(0.00)[0]$ & $0.6978^{\mathrm{a}}$ \\
\hline Myofascial pain syndrome & $1(0.44)[1]$ & $0(0.00)[0]$ & $1(2.04)[1]$ & $0(0.00)[0]$ & $0(0.00)[0]$ & $0.2178^{\mathrm{a}}$ \\
\hline Pain in extremity & $1(0.44)[1]$ & $0(0.00)[0]$ & $1(2.04)[1]$ & $0(0.00)[0]$ & $0(0.00)[0]$ & $0.2178^{\mathrm{a}}$ \\
\hline Patellofemoral pain syndrome & $1(0.44)[1]$ & $1(1.82)[1]$ & $0(0.00)[0]$ & $0(0.00)[0]$ & $0(0.00)[0]$ & $0.6978^{\mathrm{a}}$ \\
\hline Soft tissue disorder & $1(0.44)[1]$ & $1(1.82)[1]$ & $0(0.00)[0]$ & $0(0.00)[0]$ & $0(0.00)[0]$ & $0.6978^{\mathrm{a}}$ \\
\hline Endocrine disorders & $8(3.56)[9]$ & $3(5.45)[3]$ & $2(4.08)[2]$ & $0(0.00)[0]$ & $3(5.66)[4]$ & $0.1700^{\mathrm{a}}$ \\
\hline Hypothyroidism & $6(2.67)[6]$ & $2(3.64)[2]$ & $2(4.08)[2]$ & $0(0.00)[0]$ & $2(3.77)[2]$ & $0.3380^{\mathrm{a}}$ \\
\hline Autoimmune thyroiditis & $2(0.89)[2]$ & $1(1.82)[1]$ & $0(0.00)[0]$ & $0(0.00)[0]$ & $1(1.89)[1]$ & $0.5763^{\mathrm{a}}$ \\
\hline Goiter & $1(0.44)[1]$ & $0(0.00)[0]$ & $0(0.00)[0]$ & $0(0.00)[0]$ & $1(1.89)[1]$ & $0.4533^{\mathrm{a}}$ \\
\hline $\begin{array}{l}\text { Neoplasms benign, malignant and unspecified } \\
\text { (incl cysts and polyps) }\end{array}$ & $7(3.11)[7]$ & $2(3.64)[2]$ & $1(2.04)[1]$ & $2(2.94)[2]$ & $2(3.77)[2]$ & $1.0000^{\mathrm{a}}$ \\
\hline Benign neoplasm of thyroid gland & $2(0.89)[2]$ & $1(1.82)[1]$ & $0(0.00)[0]$ & $0(0.00)[0]$ & $1(1.89)[1]$ & $0.5763^{\mathrm{a}}$ \\
\hline Benign ovarian tumor & $2(0.89)[2]$ & $1(1.82)[1]$ & $1(2.04)[1]$ & $0(0.00)[0]$ & $0(0.00)[0]$ & $0.4607^{\mathrm{a}}$ \\
\hline Benign hepatic neoplasm & $1(0.44)[1]$ & $0(0.00)[0]$ & $0(0.00)[0]$ & $1(1.47)[1]$ & $0(0.00)[0]$ & $1.0000^{\mathrm{a}}$ \\
\hline Fibroadenoma of breast & $1(0.44)[1]$ & $0(0.00)[0]$ & $0(0.00)[0]$ & $1(1.47)[1]$ & $0(0.00)[0]$ & $1.0000^{\mathrm{a}}$ \\
\hline Large intestine benign neoplasm & $1(0.44)[1]$ & $0(0.00)[0]$ & $0(0.00)[0]$ & $0(0.00)[0]$ & $1(1.89)[1]$ & $0.4533^{\mathrm{a}}$ \\
\hline Metabolism and nutrition disorders & $6(2.67)[8]$ & $1(1.82)[1]$ & $0(0.00)[0]$ & $3(4.41)[5]$ & $2(3.77)[2]$ & $0.5674^{a}$ \\
\hline Diabetes mellitus & $3(1.33)[3]$ & $1(1.82)[1]$ & $0(0.00)[0]$ & $1(1.47)[1]$ & $1(1.89)[1]$ & $1.0000^{\mathrm{a}}$ \\
\hline Glucose tolerance impaired & $2(0.89)[2]$ & $0(0.00)[0]$ & $0(0.00)[0]$ & $1(1.47)[1]$ & $1(1.89)[1]$ & $0.8516^{\mathrm{a}}$ \\
\hline Hyperlipidemia & $2(0.89)[2]$ & $0(0.00)[0]$ & $0(0.00)[0]$ & $2(2.94)[2]$ & $0(0.00)[0]$ & $0.2507^{\mathrm{a}}$ \\
\hline Hypercholesterolemia & $1(0.44)[1]$ & $0(0.00)[0]$ & $0(0.00)[0]$ & $1(1.47)[1]$ & $0(0.00)[0]$ & $1.0000^{\mathrm{a}}$ \\
\hline $\begin{array}{l}\text { Respiratory, thoracic and mediastinal } \\
\text { disorders }\end{array}$ & $6(2.67)[6]$ & $2(3.64)[2]$ & $3(6.12)[3]$ & $1(1.47)[1]$ & $0(0.00)[0]$ & $0.2195^{\mathrm{a}}$ \\
\hline Rhinitis allergic & $3(1.33)[3]$ & $1(1.82)[1]$ & $1(2.04)[1]$ & $1(1.47)[1]$ & $0(0.00)[0]$ & $0.8942^{\mathrm{a}}$ \\
\hline Cough & $1(0.44)[1]$ & $1(1.82)[1]$ & $0(0.00)[0]$ & $0(0.00)[0]$ & $0(0.00)[0]$ & $0.6978^{\mathrm{a}}$ \\
\hline Oropharyngeal pain & $1(0.44)[1]$ & $0(0.00)[0]$ & $1(2.04)[1]$ & $0(0.00)[0]$ & $0(0.00)[0]$ & $0.2178^{\mathrm{a}}$ \\
\hline Restrictive pulmonary disease & $1(0.44)[1]$ & $0(0.00)[0]$ & $1(2.04)[1]$ & $0(0.00)[0]$ & $0(0.00)[0]$ & $0.2178^{\mathrm{a}}$ \\
\hline Infections and infestations & $5(2.22)[5]$ & $0(0.00)[0]$ & $2(4.08)[2]$ & $2(2.94)$ [2] & $1(1.89)[1]$ & $0.5564^{\mathrm{a}}$ \\
\hline Periodontitis & $2(0.89)[2]$ & $0(0.00)[0]$ & $1(2.04)[1]$ & $0(0.00)[0]$ & $1(1.89)[1]$ & $0.3537^{\mathrm{a}}$ \\
\hline Gastroenteritis & $1(0.44)[1]$ & $0(0.00)[0]$ & $1(2.04)[1]$ & $0(0.00)[0]$ & $0(0.00)[0]$ & $0.2178^{\mathrm{a}}$ \\
\hline Gingivitis & $1(0.44)[1]$ & $0(0.00)[0]$ & $0(0.00)[0]$ & $1(1.47)[1]$ & $0(0.00)[0]$ & $1.0000^{\mathrm{a}}$ \\
\hline Pyelonephritis chronic & $1(0.44)[1]$ & $0(0.00)[0]$ & $0(0.00)[0]$ & $1(1.47)[1]$ & $0(0.00)[0]$ & $1.0000^{\mathrm{a}}$ \\
\hline Skin and subcutaneous tissue disorders & $5(2.22)[5]$ & $1(1.82)[1]$ & $3(6.12)[3]$ & $0(0.00)[0]$ & $1(1.89)[1]$ & $0.1356^{\mathrm{a}}$ \\
\hline Androgenetic alopecia & $2(0.89)[2]$ & $1(1.82)[1]$ & $0(0.00)[0]$ & $0(0.00)[0]$ & $1(1.89)[1]$ & $0.5763^{\mathrm{a}}$ \\
\hline Chloasma & $1(0.44)[1]$ & $0(0.00)[0]$ & $1(2.04)[1]$ & $0(0.00)[0]$ & $0(0.00)[0]$ & $0.2178^{\mathrm{a}}$ \\
\hline Lentigo & $1(0.44)[1]$ & $0(0.00)[0]$ & $1(2.04)[1]$ & $0(0.00)[0]$ & $0(0.00)[0]$ & $0.2178^{\mathrm{a}}$ \\
\hline Mechanical urticaria & $1(0.44)[1]$ & $0(0.00)[0]$ & $1(2.04)[1]$ & $0(0.00)[0]$ & $0(0.00)[0]$ & $0.2178^{\mathrm{a}}$ \\
\hline Investigations & $4(1.78)[5]$ & $2(3.64)[2]$ & $0(0.00)[0]$ & $1(1.47)[2]$ & $1(1.89)[1]$ & $0.7267^{\mathrm{a}}$ \\
\hline Alanine aminotransferase increased & $1(0.44)[1]$ & $0(0.00)[0]$ & $0(0.00)[0]$ & $0(0.00)[0]$ & $1(1.89)[1]$ & $0.4533^{\mathrm{a}}$ \\
\hline Blood lactate dehydrogenase increased & $1(0.44)[1]$ & $0(0.00)[0]$ & $0(0.00)[0]$ & $1(1.47)[1]$ & $0(0.00)[0]$ & $1.0000^{\mathrm{a}}$ \\
\hline Blood pressure increased & $1(0.44)[1]$ & $1(1.82)[1]$ & $0(0.00)[0]$ & $0(0.00)[0]$ & $0(0.00)[0]$ & $0.6978^{\mathrm{a}}$ \\
\hline Transaminases increased & $1(0.44)[1]$ & $0(0.00)[0]$ & $0(0.00)[0]$ & $1(1.47)[1]$ & $0(0.00)[0]$ & $1.0000^{\mathrm{a}}$ \\
\hline Ultrasound breast abnormal & $1(0.44)[1]$ & $1(1.82)[1]$ & $0(0.00)[0]$ & $0(0.00)[0]$ & $0(0.00)[0]$ & $0.6978^{\mathrm{a}}$ \\
\hline Eye disorders & $4(1.78)[4]$ & $0(0.00)[0]$ & $2(4.08)[2]$ & $0(0.00)[0]$ & $2(3.77)[2]$ & $0.1272^{\mathrm{a}}$ \\
\hline Dry eye & $2(0.89)[2]$ & $0(0.00)[0]$ & $1(2.04)[1]$ & $0(0.00)[0]$ & $1(1.89)[1]$ & $0.3537^{\mathrm{a}}$ \\
\hline Ulcerative keratitis & $1(0.44)[1]$ & $0(0.00)[0]$ & $0(0.00)[0]$ & $0(0.00)[0]$ & $1(1.89)[1]$ & $0.4533^{\mathrm{a}}$ \\
\hline Vitreous detachment & $1(0.44)[1]$ & $0(0.00)[0]$ & $1(2.04)[1]$ & $0(0.00)[0]$ & $0(0.00)[0]$ & $0.2178^{\mathrm{a}}$ \\
\hline Reproductive system and breast disorders & $4(1.78)[4]$ & $1(1.82)[1]$ & $2(4.08)[2]$ & $1(1.47)[1]$ & $0(0.00)[0]$ & $0.5339^{\mathrm{a}}$ \\
\hline Benign prostatic hyperplasia & $1(0.44)[1]$ & $0(0.00)[0]$ & $1(2.04)[1]$ & $0(0.00)[0]$ & $0(0.00)[0]$ & $0.2178^{\mathrm{a}}$ \\
\hline Breast mass & $1(0.44)[1]$ & $0(0.00)[0]$ & $1(2.04)[1]$ & $0(0.00)[0]$ & $0(0.00)[0]$ & $0.2178^{\mathrm{a}}$ \\
\hline Fibrocystic breast disease & $1(0.44)[1]$ & $1(1.82)[1]$ & $0(0.00)[0]$ & $0(0.00)[0]$ & $0(0.00)[0]$ & $0.6978^{\mathrm{a}}$ \\
\hline Infertility male & $1(0.44)[1]$ & $0(0.00)[0]$ & $0(0.00)[0]$ & $1(1.47)[1]$ & $0(0.00)[0]$ & $1.0000^{\mathrm{a}}$ \\
\hline Congenital, familial and genetic disorders & $2(0.89)[2]$ & $0(0.00)[0]$ & $0(0.00)[0]$ & $1(1.47)[1]$ & $1(1.89)[1]$ & $0.8516^{\mathrm{a}}$ \\
\hline Type lla hyperlipidemia & $1(0.44)[1]$ & $0(0.00)[0]$ & $0(0.00)[0]$ & $1(1.47)[1]$ & $0(0.00)[0]$ & $1.0000^{\mathrm{a}}$ \\
\hline Type $V$ hyperlipidemia & $1(0.44)[1]$ & $0(0.00)[0]$ & $0(0.00)[0]$ & $0(0.00)[0]$ & $1(1.89)[1]$ & $0.4533^{\mathrm{a}}$ \\
\hline Hepatobiliary disorders & $2(0.89)[2]$ & $1(1.82)[1]$ & $0(0.00)[0]$ & $1(1.47)[1]$ & $0(0.00)[0]$ & $1.0000^{\mathrm{a}}$ \\
\hline Hepatic calcification & $1(0.44)[1]$ & $1(1.82)[1]$ & $0(0.00)[0]$ & $0(0.00)[0]$ & $0(0.00)[0]$ & $0.6978^{\mathrm{a}}$ \\
\hline Liver disorder & $1(0.44)[1]$ & $0(0.00)[0]$ & $0(0.00)[0]$ & $1(1.47)[1]$ & $0(0.00)[0]$ & $1.0000^{\mathrm{a}}$ \\
\hline Nervous system disorders & $2(0.89)[2]$ & $1(1.82)[1]$ & $0(0.00)[0]$ & $0(0.00)[0]$ & $1(1.89)[1]$ & $0.5763^{\mathrm{a}}$ \\
\hline Diabetic neuropathy & $1(0.44)[1]$ & $0(0.00)[0]$ & $0(0.00)[0]$ & $0(0.00)[0]$ & $1(1.89)[1]$ & $0.4533^{\mathrm{a}}$ \\
\hline Piriformis syndrome & $1(0.44)[1]$ & $1(1.82)[1]$ & $0(0.00)[0]$ & $0(0.00)[0]$ & $0(0.00)[0]$ & $0.6978^{\mathrm{a}}$ \\
\hline Blood and Iymphatic system disorders & $1(0.44)[1]$ & $0(0.00)[0]$ & $1(2.04)[1]$ & $0(0.00)[0]$ & $0(0.00)[0]$ & $0.2178^{\mathrm{a}}$ \\
\hline Iron deficiency anemia & $1(0.44)[1]$ & $0(0.00)[0]$ & $1(2.04)[1]$ & $0(0.00)[0]$ & $0(0.00)[0]$ & $0.2178^{\mathrm{a}}$ \\
\hline Cardiac disorders & $1(0.44)[1]$ & $0(0.00)[0]$ & $0(0.00)[0]$ & $1(1.47)[1]$ & $0(0.00)[0]$ & $1.0000^{\mathrm{a}}$ \\
\hline Ventricular extrasystoles & $1(0.44)[1]$ & $0(0.00)[0]$ & $0(0.00)[0]$ & $1(1.47)[1]$ & $0(0.00)[0]$ & $1.0000^{\mathrm{a}}$ \\
\hline Immune system disorders & $1(0.44)[1]$ & $0(0.00)[0]$ & $0(0.00)[0]$ & $0(0.00)[0]$ & $1(1.89)[1]$ & $0.4533^{\mathrm{a}}$ \\
\hline Food allergy & $1(0.44)[1]$ & $0(0.00)[0]$ & $0(0.00)[0]$ & $0(0.00)[0]$ & $1(1.89)[1]$ & $0.4533^{\mathrm{a}}$ \\
\hline Renal and urinary disorders & $1(0.44)[1]$ & $0(0.00)[0]$ & $0(0.00)[0]$ & $0(0.00)[0]$ & $1(1.89)[1]$ & $0.4533^{\mathrm{a}}$ \\
\hline Hematuria & $1(0.44)[1]$ & $0(0.00)[0]$ & $0(0.00)[0]$ & $0(0.00)[0]$ & $1(1.89)[1]$ & $0.4533^{\mathrm{a}}$ \\
\hline Surgical and medical procedures & $1(0.44)[1]$ & $0(0.00)[0]$ & $0(0.00)[0]$ & $1(1.47)[1]$ & $0(0.00)[0]$ & $1.0000^{\mathrm{a}}$ \\
\hline Dental implantation & $1(0.44)$ [1] & $0(0.00)[0]$ & $0(0.00)[0]$ & $1(1.47)[1]$ & $0(0.00)[0]$ & $1.0000^{\mathrm{a}}$ \\
\hline
\end{tabular}


Table S2 Drug compliance

\begin{tabular}{|c|c|c|c|c|c|c|}
\hline Variables & Total $(n=225)$ & $\begin{array}{l}\text { Placebo } \\
(n=55)\end{array}$ & $\begin{array}{l}\text { Synatura } \\
(n=49)\end{array}$ & $\begin{array}{l}\text { CKD-497 } 200 \mathrm{mg} \\
\quad(\mathrm{n}=68)\end{array}$ & $\begin{array}{l}\text { CKD-497 } 300 \mathrm{mg} \\
\quad(n=53)\end{array}$ & $P$ value \\
\hline Total drug compliance, mean \pm SD & $98.60 \pm 4.76$ & $99.35 \pm 3.24$ & $98.04 \pm 5.83$ & $98.97 \pm 4.15$ & $97.87 \pm 5.60$ & $0.6346^{a}$ \\
\hline \multicolumn{7}{|c|}{ Assessment of total drug compliance, $\mathrm{n}(\%)$} \\
\hline$\leq 80 \%$ or $\geq 120 \%$ & $223(99.11)$ & $55(100.0)$ & $48(97.96)$ & $68(100.0)$ & $52(98.11)$ & $0.3537^{\mathrm{b}}$ \\
\hline
\end{tabular}

${ }^{\mathrm{a}}$, Kruskal-Wallis test; ${ }^{\mathrm{b}}$, Fisher's exact test. SD, standard deviation.

Table S3 Secondary efficacy analysis of BSS (cough and phlegm)

\begin{tabular}{|c|c|c|c|c|}
\hline Variables & Placebo $(n=55)$ & Synatura $(n=49)$ & CKD-497 200 mg (n=68) & CKD-497 300 mg $(n=53)$ \\
\hline Baseline (visit 1), mean (SD) & $2.47(0.54)$ & $2.45(0.54)$ & $2.54(0.56)$ & $2.58(0.53)$ \\
\hline Day 4 (visit 2), mean (SD) & $1.56(0.76)$ & $1.35(0.66)$ & $1.40(0.79)$ & $1.45(0.72)$ \\
\hline Day 7 (visit 3), mean (SD) & $0.80(0.85)$ & $0.63(0.76)$ & $0.81(0.82)$ & $0.68(0.78)$ \\
\hline$P$ value $^{2}$ & & & 0.6346 & \\
\hline \multicolumn{5}{|l|}{ Phlegm } \\
\hline Baseline (visit 1), mean (SD) & $2.40(0.53)$ & $2.35(0.48)$ & $2.25(0.44)$ & $2.25(0.43)$ \\
\hline Day 4 (visit 2), mean (SD) & $1.56(0.90)$ & $1.35(0.72)$ & $1.43(0.65)$ & $1.13(0.71)$ \\
\hline$P$ value $^{2}$ & & & 0.6404 & \\
\hline
\end{tabular}

${ }^{1}$, result of Kruskal-Wallis test comparing group's average of changes between day 4 (visit 2) and baseline (visit 1); ${ }^{2}$, result of KruskalWallis test comparing group's average of changes between day 7 (visit 3) and baseline (visit 1). BSS, bronchitis severity score; SD, standard deviation.

Table S4 Analysis of covariance with an adjustment for a baseline value

\begin{tabular}{|c|c|c|c|c|}
\hline Variables (BSS total) & Placebo $(n=55)$ & Synatura $(n=49)$ & CKD-497 200 mg $(n=68)$ & CKD-497 $300 \mathrm{mg}(\mathrm{n}=53)$ \\
\hline Day 4 (visit 2), mean (SD) & $3.56(2.32)$ & $2.88(1.36)$ & $3.10(1.53)$ & $2.85(1.59)$ \\
\hline Day 7 (visit 3), mean (SD) & $1.78(2.02)$ & $1.33(1.28)$ & $1.59(1.37)$ & $1.43(1.77)$ \\
\hline$P$ value $^{1}$ & \multicolumn{4}{|c|}{0.1488} \\
\hline
\end{tabular}


Table S5 Secondary effectiveness analysis of BSS (cough baseline score $\geq 3$ )

\begin{tabular}{lcccc}
\hline Variables (cough) & Placebo $(\mathrm{n}=25)$ & Synatura $(\mathrm{n}=21)$ & CKD-497 200 mg $(\mathrm{n}=35)$ & CKD-497 300 mg $(\mathrm{n}=30)$ \\
\hline Baseline (visit 1), mean (SD) & $6.20(1.44)$ & $5.76(0.89)$ & $5.86(1.17)$ & $5.97(0.96)$ \\
Day 4 (visit 2), mean (SD) & $4.00(3.06)$ & $3.10(1.58)$ & $3.37(1.72)$ & $3.30(1.86)$ \\
Day 7 (visit 3), mean (SD) & $2.20(2.65)$ & $1.57(1.50)$ & $1.94(1.53)$ & $1.87(2.16)$ \\
P value $^{1}$ & & & 0.9144 & 0.7948 \\
P value $^{2}$ & & & & \\
\hline
\end{tabular}

${ }^{1}$, result of Kruskal-Wallis test comparing group's average of changes between day 4 (visit 2) and baseline (visit 1); ${ }^{2}$, result of KruskalWallis test comparing group's average of changes between day 7 (visit 3) and baseline (visit 1). BSS, bronchitis severity score; SD, standard deviation.

Table S6 Secondary effectiveness analysis of BSS (phlegm baseline score $\geq 3$ )

\begin{tabular}{lcccc}
\hline Variables (phlegm) & Placebo $(\mathrm{n}=21)$ & Synatura $(\mathrm{n}=17)$ & CKD-497 200 mg $(\mathrm{n}=17)$ & CKD-497 300 mg $(\mathrm{n}=13)$ \\
\hline Baseline (visit 1), mean (SD) & $6.24(1.55)$ & $5.88(0.93)$ & $6.29(1.40)$ & $6.46(1.13)$ \\
Day 4 (visit 2), mean (SD) & $5.00(2.95)$ & $3.35(1.77)$ & $3.59(1.87)$ & $3.77(2.55)$ \\
Day 7 (visit 3), mean (SD) & $2.76(2.81)$ & $1.53(1.46)$ & $1.76(1.52)$ & $2.15(3.08)$ \\
P value $^{1}$ & & & 0.0421 & 0.5598 \\
P value $^{2}$ & & & & \\
\hline
\end{tabular}

${ }^{1}$, result of Kruskal-Wallis test comparing group's average of changes between day 4 (visit 2) and baseline (visit 1); ${ }^{2}$, result of KruskalWallis test comparing group's average of changes between day 7 (visit 3) and baseline (visit 1). BSS, bronchitis severity score; SD, standard deviation. 